\title{
The Effect of Group Boundary Permeability on Intergroup Prejudice: The Case of Rural-to-Urban Migrants in China
}

\author{
Xiao-xiao Zhang, ${ }^{1}$ Jian Zheng, ${ }^{1}$ Li Liu, ${ }^{1}$ Xian Zhao, ${ }^{1,2}$ and Xiao-min Sun ${ }^{1}$ \\ 1 School of Psychology, Beijing Normal University, Beijing Key Lab of Applied Experimental Psychology, Beijing, China \\ 2 Department of Psychology, University of Kansas, Lawrence, Kansas, USA
}

\begin{abstract}
T he developing world is witness to a major urban transformation. How to facilitate intergroup relations between new migrants and long-time urban residents is a critical issue in developing societies globally. The current research explored the effect of group boundary permeability on intergroup prejudice by the case of rural-to-urban migration in China. As the boundary between rural-to-urban migrants and permanent urban residents in China can be ascribed to China's unique hukou system, we conducted three interrelated studies to approach the topic from the perspective of the hukou system and its reforms. Study 1 used a correlational investigation and found a negative correlation between group boundary permeability and prejudice against rural-to-urban migrants. In Study 2, we manipulated the group boundary permeability using the points accumulation system scheme of the hukou system reform, and found a causal effect of the group boundary permeability on the social distance of urban dwellers to migrants. In Study 3, using a more general hukou reform scheme, that of gradually abolishing the hukou system, we replicated the findings from Study 2 and further found that a permeable group boundary could reduce prejudice. These three studies suggest that the group boundary based on the Chinese hukou system is an institutional cause of prejudice against rural-to-urban migrants. Our experimental manipulations can be interpreted as analogues to potential policy arena actions.
\end{abstract}

Keywords: group boundary permeability, intergroup prejudice, rural-to-urban migrants, hukou system

The developing world is witness to a major urban transformation. Much of the rural population is abandoning agriculture and moving to urban areas. Rural-to-urban migration has been the most salient internal migration phenomenon across Asia, Africa and Latin America. It is expected that by 2030, each of the major regions of developing countries will be home to more urban dwellers than rural dwellers, and by 2050, two thirds of their inhabitants are likely to live in urban areas (Montgomery, 2008). The annual data shows that the total number of rural-to-urban migrants in China was over 260 million in the year 2013 (National Bureau of Statistics of China, 2013), exceeding even the population of Indonesia, which has the fourth largest population in the world. Rural-tourban migrants contribute greatly to the industrialisation, modernisation and urbanisation of cities. However, they tend to be socially segregated from the urban host population in many developing countries. For instance, ruralto-urban migrants are treated as 'disadvantaged others' and 'threatening others' in Turkey (Erman, 2001), and they must work in primarily unskilled, casual and lowpaid jobs in India (Mosse et al., 2002). In China, these migrants are represented as a socially inferior group, and considered as aggressive, fatuous, old-fashioned and conservative (Guan \& Liu, 2013). They experience prejudice from urban residents (e.g., Li et al., 2007; Roberts, 2001; Yang, Tian, van Oudenhoven, Hofstra, \& Wang, 2010). The aim of the current research was to explore the impact of group boundary permeability on prejudice against rural-to-urban migrants.

\section{Rural-to-Urban Migration and the Hukou System in China}

The boundary between rural-to-urban migrants and permanent urban residents in China can be ascribed to China's unique hukou system (Chan \& Buckingham, 2008; Wang, 2005), which refers to the household registration system. From the early 1950s to the late 1970s, China

Address for correspondence: Prof Li Liu, School of Psychology, Beijing Normal University, Beijing 100875, China. Email: l.liu@bnu.edu.cn 
maintained a tight control over rural-to-urban mobility by the hukou system (Young, 2010, 2013). Every citizen was required to register at his/her permanent residence. One's hukou status was inherited from one's mother and was thus predetermined. Every citizen was thus given a geographically defined location and an associated sociopolitical status and identity (Wang, 2005). While initially conceived as an instrument for migration control, the hukou system was soon transformed into a social institution that divided Chinese society into spatial hierarchies whose sharpest division was between 'agricultural' and 'non-agricultural' registration status (Mallee, 2000; Wu \& Treiman, 2004). The essential distinction between these two categories of citizens was their relation to the state. Individuals registered as the 'agricultural' (rural) category depended mainly for their livelihood on their own labour and the fluctuating harvests. Social welfare provisions such as education and medical service were supported by the villagers themselves, and maintained at a low level. Individuals registered as the 'non-agricultural' (urban) category, on the other hand, were issued with rationed coupons for daily necessities such as grain, cooking oil and cotton clothes, and were eligible for housing provision and other major social welfare provided by the government. Labour influx from rural to urban areas was rigidly controlled by the government. Urban residents were thus seen as superior to rural residents in terms of both social reputations and tangible advantages.

China's liberal economic reform since 1978 has created millions of jobs in urban areas on the one hand, and significantly decreased arable land in rural areas and produced millions of surplus rural labourers on the other (Yang et al., 2010). The control over the rural-to-urban mobility by the hukou system has become less effective. For example, the total migrant population by the mid1990s had reached 80 million (Mallee, 2000), certainly making China's recent peacetime population movement the largest in history. The term rural-to-urban migrants has gained its currency to depict rural labour flows. Rural-tourban migration plays a double role: remedying hardcore rural poverty and lowering urban-rural inequality. However, it is almost impossible for the people who come from rural areas to work in cities to change their hukou from the 'agricultural' to the 'non-agricultural' category. In 1985, the government introduced a renewable temporary residency permit for the purpose of residency and employment of rural-to-urban migrants (Young, 2010). It is an important change to the hukou system because the permit made it legal for people with agricultural or nonlocal hukou status (those with hukou registered outside of where they are residing, working and living) to work and reside in a specific urban area. This permit thus highlights another division of the hukou system, 'local' and 'nonlocal' registration statuses. As 'outsiders', the migrants are segregated from the urban host population. They are considered as 'rustics' by urban residents, and maltreated at work. They remain ineligible for many benefits enjoyed by those with a local urban identity, such as housing, social insurance and child education services. Although the hukou system is no longer used to prevent rural-to-urban mobility, Chinese society can still, by and large, be divided into 'agricultural' and 'non-agricultural' segments.

Further reform of the hukou system has been widely discussed and piloted in several places (Chan \& Buckingham, 2008). Basically, there are two different schemes for carrying out the reform. One advocates that reform should be gradually carried out based on different people's qualifications. According to this scheme, well-educated migrants have first priority, followed by skilled workers, and last are low-education or low-skilled workers (Chan, 2013). The reform scheme is termed as the 'points accumulation system' (Zheng, 2010). Under this scheme, migrants can be granted non-agricultural hukou status subject to certain qualifications related to eligibility criteria. Eligibility is assessed quantitatively by several criteria, such as educational attainment, professional qualifications, and investment and tax payable. Only those who reach the required points are eligible to obtain non-agricultural status. That is, the migrants are expected to obtain non-agricultural hukou status through their own efforts. Under this reform scheme, those who are well educated, well skilled, or pay more taxes have priority (Chan, 2013).

Another scheme for the reform is based on city size. According to this scheme, the hukou system reform should be carried out in small cities first, then gradually expanded to middle-sized and large cities (Wang, 2002). Under this scheme, the hukou system would be gradually removed in some small and medium-sized cities, integrating the migrant population into local society. However, there are some restrictions when applying this scheme to metropolises such as Beijing and Shanghai (Chan \& Buckingham, 2008).

Overall, the hukou system reform is aimed at diminishing the differences, and removing the group boundary between the permanent urban residents and rural-to-urban migrants. Both schemes consider the hukou system reform as a 'step-by-step' process. However, the hukou system in general remains potent, although both schemes have been tested in some areas (see Li, Li, \& Chen, 2010; Melander \& Pelikanova, 2013). It continues to function as an institutionally imposed group boundary dividing rural and urban populations and perpetuating China's rural-urban disparity. The hukou system thus is perceived as a system of 'cities with invisible walls' in China (Chan, 1994).

The impact of the hukou system reform has attracted attention from social scientists (Cai, 2011; Chan, 2013; Li et al., 2010; Wang, 2002). In general, the hukou system reform promotes labour mobility from rural to urban sectors, thus increasing internal migration (Cai, 2011). As a result, on the bright side, labour mobility can largely fulfill the requirements of industry (Chan, 2013) and contribute to the rapid growth of the economy and the process of the urbanisation. The reform also reduces the inequality between the local urban population and rural migrants 
(Zhao \& Howden-Chapman, 2010), as well as reducing dramatically the urban-rural income gap (Hertel \& Zhai, 2006). On the other hand, the hukou system reform puts great pressure on local governments since it requires increased government spending in many areas, such as education, health and pension services (An, 2013).

\section{Effect of Group Boundary Permeability on Prejudice Against the Migrants}

The Chinese hukou system and its recent reforms provide a natural laboratory for exploring the effect of group boundary permeability on intergroup prejudice. The concept of group boundary permeability is derived from social identity theory (Tajfel \& Turner, 1979). It refers to the extent to which individual group members can leave one group and join another (Tajfel \& Turner, 1979, 1986; see also Verkuyten \& Reijerse, 2008). Group boundary permeability is a social-structural characteristic of intergroup relations (Ellemers, van Knippenberg, Vries, \& Wilke, 1988) and a type of subjective belief (Johnson, Terry, \& Louis, 2005; Verkuyten \& Reijerse, 2008).

The group boundary makes group-based social categories salient, which in turn provides a basis for intergroup prejudice (Tajfel, Billig, Bundy, \& Flament, 1971). The impermeability of a group boundary can cause severe social exclusion. For example, Turkish people in Germany, even into the third generation, are perpetually treated as temporary visitors. In 2002, by which time Turks had been coming to Germany for 41 years and numbered 2.5 million, only 470,000 had managed to attain German citizenship. Perhaps because of their lack of citizenship, many Turks in Germany still cannot speak German, and their unemployment rates are at least twice those of Germans. The places inhabited by these immigrants are still referred to as 'urban villages' (Aparicio, 2007).

However, when the group boundary is permeable, members of the two different groups may be recognised as members of one integrated group, reducing intergroup prejudice (Dovidio, Glick, \& Rudman, 2005). Florack, Piontkowski, Rohmann, Balzer, and Perzig (2003) indicated that when the group boundary between Germany and Turkish immigrants was believed to be permeable, immigrants were assumed to be able to assimilate by the host community and were less likely to be segregated and excluded. Furthermore, based on system justification theory, Kuang and Liu (2012) indicated the priming of the proposed abolishment of the current hukou system led to reduced social distance against rural-to-urban migrants. Indeed, there are some different findings in literature. For example, Johnson, Terry, and Louis (2005) found that when white Australians evaluated their position as unstable and high status or legitimate, perceived permeable intergroup boundaries were associated with prejudice against Asian Australians.

However, it is worth noting that the boundaries between groups are created in different contexts. The group boundaries were either exogenous or endogenous in these apparently contradictory findings. For example, groups can be perceived as homogenous: the group boundary was socially constructed through nationality in Florack et al.'s (2003) study, and through the hukou system in Kuang and Liu's (2012) study. On the other hand, groups can be perceived as heterogenous if the group boundary is innate and created by race, as in Johnson et al.'s (2005) study. For the current research, the group boundary between urban permanent residents and rural-to-urban migrants was exogenously caused by the hukou system. Thus, we specifically predicted that group boundary permeability is negatively correlated with prejudice against rural-to-urban migrants (Hypothesis 1) and a permeable group boundary reduces prejudice against the migrants (Hypothesis 2).

\section{Overview of the Current Research}

In the current research, we used both correlational and experimental designs to examine the extent to which the group boundary permeability impacts upon prejudice against rural-to-urban migrants in China. Three studies were conducted to test our predictions. Hypothesis 1 was tested in Study 1, in which the association between group boundary permeability and prejudice against rural-tourban migrants was investigated. Hypothesis 2 was tested by Study 2 and Study 3. In Study 2, the causal effect of the group boundary permeability on intergroup prejudice was examined by experimentally manipulating the group boundary permeability, using one scheme for the hukou system reform, the points accumulation system. In Study 3, we further confirmed the results of Study 2 using a different manipulation, a more general reform scheme, gradually abolishing the hukou system.

\section{STUDY 1 \\ Methods}

\section{Participants}

In total, 161 undergraduate students ( 83 female, 78 male) from the Beijing Institute of Fashion Technology participated the study. All of the participants were registered in the non-agricultural hukou category when enrolled in the study. The average age of the participants was 20.95 years $(S D=1.14)$.

\section{Measures}

Group boundary permeability measure. A six-item group boundary permeability scale adapted from Mummendey, Klink, Mielke, Wenzel, and Blanz (1999) was used to measure the perceived group boundary permeability between rural-to-urban migrants and permanent urban residents. The participants chose a number from 1 to 7 to indicate their levels of agreement with items such as 'No matter what effort she/he makes, a rural-to-urban migrant can never become an urban resident' (reverse-scored). Higher scores represented perceiving the boundary between rural-to-urban migrants and urban residents as more 
Table 1

Descriptive Statistics and Correlation Matrix for Study 1

\begin{tabular}{llllll}
\hline Variable & $N$ & $M$ & $S D$ & 1 & 2 \\
\hline 1 Permeability & 161 & 4.50 & 0.99 & - & \\
2 Prejudice & 161 & 2.93 & 0.90 & $-0.343^{* *}$ & - \\
3 Social desirability & 161 & 4.58 & 0.86 & $0.178^{*}$ & 0.059
\end{tabular}

Note: ${ }^{*} p<.05 .{ }^{* *} p<.01$.

permeable. The average score of the six items was calculated as an indicator of group boundary permeability (Cronbach's $\alpha=0.790$ ).

Prejudice measure. The prejudice against rural-to-urban migrants was measured by an adapted six-item Symbolic Racism 2000 (SR2K) scale (Henry \& Sears, 2002). The items were rephrased according to the Chinese migration situation. The scale tapped into subtle and indirect prejudice from the perspective of social beliefs. On a 7-point Likert scale $(1=$ strongly disagree; $7=$ strongly agree $)$, the participants indicated the extent to which they endorsed such statements as 'Over the past few years, rural-to-urban migrants have received more economically than they deserve. Higher scores represented stronger prejudices. The average score of the six items was calculated as a prejudice indicator (Cronbach's $\alpha=0.687$ ).

Social desirability measure. The participants were required to complete a short version of the MarloweCrowne Social Desirability Scale (Crowne \& Marlowe, 1960; Robinson, Shaver, Wrightsman, \& Andrews, 1997) to control for socially desirable responses. The scale contains 12 items. The participants were asked to choose a number from 1 to 7 to indicate their level of agreement with such items as 'It is sometimes hard for me to go on with my work if I am not encouraged'. Higher scores represented higher levels of social desirability. The average score of the 12 items was calculated as an indicator of socially desirable responding (Cronbach's $\alpha=0.771$ ).

\section{Procedure}

The participants completed the questionnaires individually in classrooms. After the study, each participant was paid $\mathrm{RMB} \cdot 5$ for their participation.

\section{Results and Discussion}

The descriptive analysis and correlations between the three continuous variables are presented in Table 1. As shown in Table 1, group boundary permeability was significantly negatively correlated with prejudice, and social desirability had no significant correlation with prejudice.

Regression analysis confirmed our prediction that higher perceived group boundary permeability predicted lower prejudice against rural-to-urban migrants $(\beta=$ $\left.-0.317, t(160)=-4.68, p<0.001, R^{2}=0.112\right)$ after controlling for social desirability. These results are consistent with the previous literature indicating that group boundary permeability is negatively associated with prejudice (Florack et al., 2003). Hypothesis 1 was thus confirmed.

\section{STUDY 2}

Study 1 revealed an association between group boundary permeability and prejudice against rural-to-urban migrants. However, the correlational design of Study 1 did not allow for the investigation of the causal impact of group boundary permeability on intergroup prejudice. To overcome this limitation, an experimental manipulation of group boundary permeability was used in Study 2. Furthermore, we manipulated group boundary permeability with a specific hukou system reform scheme, the points accumulation system. We hypothesised that a permeable group boundary would lead to less prejudice against rural-to-urban migrants relative to an impermeable group boundary.

\section{Method \\ Participants}

In total, 59 college students (40 female, 19 male) from Beijing Normal University were recruited to participate in Study 2. All of the participants were registered in the nonagricultural hukou category when enrolled in the study. The average age of the participants was 22.73 years $(S D=$ $2.80)$. The participants were randomly assigned to one of two between-subjects priming conditions: permeable ( $n=$ $29)$ versus impermeable $(n=30)$.

\section{Materials}

Priming for group boundary permeability. The group boundary permeability was primed by one of two mock articles. In the permeable condition, the participants read an article reporting that a rural-to-urban migrant had managed to obtain non-agricultural hukou status in Guangzhou city due to the points accumulation system. In the impermeable condition, the participants read an article indicating that due to the failure of the points accumulation system, rural-to-urban migrants still could obtain non-agricultural hukou status in Guangzhou. It was also mentioned in both articles that the situation in Guangzhou, a pilot city for the hukou system reform, reflects the overall process of rural-to-urban migration in China.

Manipulation check. To verify the effect of these manipulations, after reading, the participants were asked to complete a two-item manipulation check. These items were 'What is the probability of a rural-to-urban migrant becoming an urban resident in the current situation?' and 'How easily do rural-to-urban migrants become urban residents in the current situation?' The participants were asked to choose a number from 1 to 7 to indicate their level of agreement with each item. The two items were highly positively correlated, $r(59)=0.503, p<.01$. We used the average score of the two items as an index of permeability. 
Social distance measure. The participants were asked to complete a six-item Social Distance Scale adapted from Crandall (1991). The items were rephrased according to the Chinese rural-to-urban migration situation. The scale tapped into subtle prejudice from the perspective of effective distance. On a 7-point Likert scale $(1=$ strongly disagree; $7=$ strongly agree), they indicated the extent to which they endorsed such statements as 'I would like to work with rural-to-urban migrants' (reverse-scored). Higher scores represented stronger prejudices. The average score of the six items was calculated as a prejudice indicator (Cronbach's $\alpha=0.789$ ).

Social desirability measure. The participants were also asked to complete the 16-item Responding Desirably on Attitudes and Options Scale (RD-16, Schuessler, Hittle, \& Cardascia, 1978). On a 7-point scale ranging from 1 (completely disagree) to 7 (completely agree), they indicated the extent to which they endorsed such statements as 'I find that I can help others in many ways'. Higher scores represented higher levels of social desirability. The average score of the 16 items was calculated as an indicator of socially desirable responding (Cronbach's $\alpha=0.827$ ).

\section{Procedure}

The participants were instructed to read the priming material, answer manipulation check questions, and then complete the social distance measure and social desirability measure in that order. At the end of the study, each of the participants received $\mathrm{RMB} \cdot 10$ for their participation.

\section{Results and Discussion}

The manipulation check showed that the permeability scores were higher in the permeable condition $(M=3.52$, $S D=0.91)$ than in the impermeable condition $(M=2.40$, $S D=0.72 ; t=5.22), p<.001$, Cohen's $d=1.24$. This result suggested that the manipulation was successful.

There was a significantly negative correlation between social desirability and social distance against rural-tourban migrants $(r=-.451, p<.001)$, indicating that social desirability should be controlled for when comparing the effect of group boundary permeability across the two groups. Subsequently, we regressed social distance onto group category (we recorded group category using contrast coding, permeable condition $=1$, impermeable condition $=-1$ ) and controlled for social desirability. We examined whether the manipulated group boundary permeability condition predicted social distance from the rural-to-urban migrants. The findings revealed that the effect of group boundary permeability on social distance was significant, $\beta=0.25, t(57)=-2.456, p<.05, R^{2}=$ .245. The scores for social distance were lower in the permeable condition $(M=2.69, S D=0.75)$ than in the impermeable condition $(M=3.10, S D=0.95)$, Cohen's $d=$ -0.44 . The results suggested that the participants reported less prejudice when the group boundary was primed to be permeable than when it was primed to be impermeable.
Consistent with our prediction, when priming a permeable group boundary, the participants showed lower levels of prejudice against rural-to-urban migrants. This result provided additional experimental support for previous work asserting that intergroup prejudice can be affected by group boundary permeability (Florack et al., 2003). The findings of Study 2 further confirmed the negative correlation between group boundary permeability and prejudice found in Study 1. The prejudice against rural-to-urban migrants may be lower when the boundary between rural and urban residents is permeable relative to when the boundary is impermeable. The findings of Study 2 also indicated that the points accumulation system might play a positive role in intergroup relations between urban residents and rural-to-urban migrants in China. The reform scheme of the points accumulation system is an efficient way in phasing out the hukou system in terms of facilitating the intergroup relations. However, Study 2 is limited in that it did not demonstrate whether the permeable group boundary could reduce prejudice, or the impermeable group boundary could increase prejudice due to the lack of a control condition.

\section{STUDY 3}

In Study 3, we aimed to replicate the findings from Study 2 using a different manipulation of group boundary permeability, namely, gradually abolishing or preserving the hukou system. We further added a control condition to the research design in Study 3. We predicted that among the three conditions, the permeable group boundary would lead to the least social distance.

\section{Method \\ Participants}

In total, 112 (24 male, 78 female) students from Beijing Normal University participated in this study. All of the participants were registered in the non-agricultural hukou category when enrolled in the study. The average age of the participants was 24.10 years $(S D=5.24)$. The participants were randomly assigned to one of three between-subjects priming conditions: permeable $(n=37)$, impermeable $(n=39)$ and control $(n=36)$.

\section{Materials}

Priming for group boundary permeability. Group boundary permeability was primed by one of three mock articles. In the permeable condition, the participants read an article reporting that 'the Chinese government has announced that the agricultural and non-agricultural hukou distinction is expected to be gradually eliminated in 2018. In the impermeable condition, the participants read an article indicating that the Chinese government has announced that the reform of agricultural and nonagricultural hukou distinction requires more investigation and that the current hukou system will be retained for the foreseeable future'. Both mock articles were adapted from 
Kuang and Liu (2012). In the control condition, the participants were asked to read an irrelevant article describing a flight delay caused by weather.

To verify the effect of these manipulations, after reading, the participants were asked to complete a six-item group boundary permeability scale (the same as used in Study 1) as the manipulation check. The average score of the nine items was calculated as the index of permeability (Cronbach's $\alpha=0.748$ ).

Social distance measure. A nine-item adapted Bogardus Social Distance Scale (Bogardus, 1925) was used to measure prejudice. The items were rephrased according to the Chinese rural-to-urban migration situation. The scale tapped into subtle prejudice from the perspective of effective distance. On a 7-point Likert scale $(1=$ strongly disagree; $7=$ strongly agree), the participants indicated the extent to which they endorsed such statements as 'I tend to avoid rural-to-urban migrants'. Higher scores represented stronger prejudices. The average score of the nine items was calculated as a prejudice indicator (Cronbach's $\alpha=$ $0.853)$.

Social desirability measure. The RD-16 scale (the same as used in Study 2) was used to measure participants' socially desirable responses. The items were rated on a 7-point scale ranging from 1 (completely disagree) to 7 (completely agree). Higher scores represented higher levels of social desirability. The average score of the 16 items was calculated as an indicator of socially desirable responding (Cronbach's $\alpha=0.839$ ).

\section{Procedure}

The participants were instructed to read the priming material and then answer the manipulation check questions. Next, they were asked to complete the social distance measure and the social desirability measure. At the end of the study, each of the participants received RMB $\cdot 5$ for their participation.

\section{Results and Discussion}

Participants in the permeable condition perceived the group boundary between rural-to-urban migrants and urban residents as being the most permeable $(M=5.38$, $S D=0.87)$. In the control condition, the perceived group boundary permeability was moderate $(M=4.47, S D=$ 1.01). Participants in the impermeable condition perceived lowest permeability of the group boundary $(M=$ $3.70, S D=0.96)$. The measure of group boundary permeability was analysed using a one-way ANOVA. A betweensubjects effect was found for salience, $F(2,110)=26.69$, $p<0.001, \eta_{p}{ }^{2}=0.35$. LSD tests indicated that the results of the pairwise comparisons were all significant $\left(M_{\text {(permeable-impermeable })}=1.68, S D_{\text {(permeable-impermeable })}=\right.$ $0.22, p<.001$, Cohen's $d=0.72 ; M_{\text {(permeable-control) }}=0.91$, $S D_{\text {(permeable-control) }}=0.22, p<.001$, Cohen's $d=0.71$; $M_{\text {(control-impermeable) }}=0.77, S D_{\text {(control-impermeable) }}=0.22$,

\section{Table 2}

ANCOVA Results for the Between-Subjects Effects on Social Distance in Study 3

\begin{tabular}{lrrrr}
\hline Source & $d f$ & \multicolumn{1}{l}{ SS } & \multicolumn{1}{c}{ MS } & \multicolumn{1}{l}{$F$} \\
\hline Corrected model & 3 & $20.101^{\mathrm{a}}$ & 6.700 & $8.666^{* * *}$ \\
Intercept & 1 & 57.450 & 57.450 & $74.301^{* * *}$ \\
conditions & 2 & 7.620 & 3.810 & $4.928^{* *}$ \\
Social desirability & 1 & 7.194 & 7.194 & $9.305^{* *}$ \\
Error & 108 & 83.506 & .773 & \\
Total & 112 & 1269.696 & & \\
Corrected total & 111 & 103.607 & & \\
\hline Note: ${ }^{a}{ }^{2}=0.194,\left(\Delta \mathrm{R}^{2}=0.172\right) .{ }^{* * *} \mathrm{p}<.001,{ }^{* *} \mathrm{p}<.01$. &
\end{tabular}

$p<.01$, Cohen's $d=0.71)$. Thus, the manipulation was successful.

The bivariate correlation results showed that there was a significantly negative correlation between social desirability and social distance against rural-to-urban migrants, $r=-0.347, p<.001$, and no interaction effect for condition $\times$ social desirability on social distance, $F(32$, $34)=1.393, p=.172$. Therefore, we further conducted an ANCOVA (analysis of covariance) to help test the effect of group boundary permeability on social distance against the rural-to-urban migrants. The ANCOVA results are presented in Table 2.

The findings showed a significant effect of experimental condition on social distance after controlling for social desirability, $F(2,108)=4.928, p<0.01, \Delta R^{2}=0.172$, which revealed that the participants' prejudice against the rural-to-urban migrants varied by condition. Furthermore, planned contrasts revealed that participants showed less social distance in the permeable condition $(M=2.75$, $S D=0.95)$ than in the control condition $(M=3.42, S D$ $=0.79), p<.05$, Cohen's $d=-0.72$, and there were no differences in the scores for social distance between the impermeable condition $(M=3.50, S D=0.98)$ and control condition, $p>.05$. The findings indicated that a permeable group boundary reduced intergroup prejudice. Thus, Hypothesis 2 was confirmed.

In Study 3, we found that prejudice against rural-tourban migrants can be reduced by priming a permeable group boundary. The findings indicated that gradually abolishing the hukou system also had an effect on facilitating intergroup relations between rural-to-urban migrants and urban permanent residents in China.

\section{General Discussion}

The results of these three studies supported our hypotheses about the effects of group boundary permeability on prejudice against rural-to-urban migrants: Group boundary permeability is negatively correlated with prejudice against rural-to-urban migrants (Hypothesis 1), and permeable group boundaries can reduce prejudice against the migrants (Hypothesis 2). The findings thus verify the validity of social identity theory (Tajfel \& Turner, 1979), and provide group-based explanations for prejudice against rural-to-urban migrants. 
We experimentally manipulated group boundary permeability using the two different schemes of the hukou system reform. On the one hand, the current research extends the work of Ellemers et al. (1988) and Ellemers, Wilke, and van Knippenberg (1993), which manipulates group boundary permeability based on a fictitious situation, whereas the current research manipulated group permeability based on the real situation in China. On the other hand, our successful manipulation revealed the covariation between objective group boundary permeability and perceived group boundary permeability. It also demonstrated that the hukou system in China provides not only an institutional boundary but also a psychological boundary. Hence, it is necessary to reform the current hukou system in China to make the psychological boundary between the urban permanent residents and rural-tourban migrants more permeable, leading to less prejudice against rural-to-urban migrants.

The findings of the current research pose an important scientific question: Why does an alternative hypothesis, that a permeable group boundary would threaten the urban group and consequently would trigger prejudice against rural-to-urban migrants, not work in China? Indeed, in Johnson et al.'s (2005) study, the group boundary between white Australians and Asian Australians is inherent in the form of race, and thus permeability refers to a reduction in status differences between two inherently different groups. Under these conditions, a permeable group boundary caused white Australians to experience a threat to their dominance, and thereby facilitated the prejudice against Asian Australians. However, there are no inherent differences between permanent urban residents and rural-to-urban migrants in China. The group boundary in the current research is caused by the social institution of the hukou system. Under this specific condition, when the group boundary is permeable, urban permanent residents perceive a more common in-group identity with the migrants, which in turn reduces the prejudice against the migrants. We thereby argue that the perceptions of heterogeneity/homogeneity between groups would be a potential moderator of the relationship between group boundary permeability and intergroup prejudice. The different groups can be perceived as heterogenous groups when a group category is based on biological classification, such as skin color and race. In this case, group boundary permeability can facilitate prejudice. On the other hand, the different groups can be perceived as a homogenous group when a group category is based on social classification, such as nationality and hukou system. In this case, group boundary permeability can reduce prejudice. We hope that this theoretical account can move the literature forward by stimulating further research for moderating factors in the relationships between group boundary permeability and prejudice.

Indeed, as stated in 'China's urbanization plan 20142020' (Xinhua News Agency, 2014), released by the government, urbanisation is the road that China must follow in its modernisation drive, and it serves as a strong engine for sustainable and healthy economic growth in China. This poses an important question to policy-makers and social scientists: How can Chinese society escape from the social chaos caused by an increasing flow of agricultural population to cities? It is evident that intergroup prejudice is a chief culprit of social chaos (Buys \& Bebeau, 1971; Fishman, 2000). For example, both the St Paul's street disturbances of 1980 and the British riots of 1958 were rooted in racism (Litton \& Potter, 1985; Miles, 1984). To facilitate intergroup relations between the migrants and permanent urban residents is thus a critical issue in this evolving challenge of society. The current research has shown that the hukou system reforms can help to improve intergroup relations in terms of reducing prejudice against rural-to-urban migrants. Although the reform schemes are 'easy-to-difficult' processes (Chan, 2013) and just beginning to be carried out, our research suggests that they do indeed contribute to eliminating intergroup prejudice and facilitating social integration in China. In this sense, the current empirical research can become part of social action to improve decision-making in an important public policy domain.

In conclusion, the current research has confirmed with three interrelated studies that group boundary based on the Chinese hukou system is an institutional cause of prejudice against rural-to-urban migrants. From a practical perspective, our experimental manipulations can be interpreted as analogues to potential policy arena actions. However, as Gergen (1973) argues, unlike natural science, the study of social psychology is primarily a historical undertaking. The current research does not aim at uncovering the transhistorical generalisations of prejudice against rural-to-urban migration in China. Rather, it intends to achieve a better understanding of the phenomenon at a particular point in time. In addition, the findings from the current research also provide the possibilities of further examining how significant changes concerning the object of study occur over time, and of exploring the reasons of political reforms behind these transformations. By doing so, the research will further capture the dynamics of intergroup relations between new migrants and permanent urban residents and operate towards both continuity and change. These tasks remain to be the agenda of the future studies.

\section{Acknowledgments}

This research was supported by the Major Project of National Social Science Foundation (13\&ZD073) and by the MOE Project of the Key Research Institute of Humanities and Social Sciences in University (2009JJDXLX001). The authors would like to thank Dr Dong Liu for his help in data analysis. The authors are also grateful to Professor James H. Liu for his constructive suggestions on the earlier versions of the manuscript. 


\section{References}

Aparicio, R. (2007). The integration of the second and 1.5 generations of Moroccan, Dominican and Peruvian origin in Madrid and Barcelona. Journal of Ethnic and Migration Studies, 33(7), 1169-1193.

An, B.J. (2013, Dec 18). Hukou reforms target 2020: Official. Retrieved April 29, 2014, from http://europe.chinadaily. com.cn/china/2013-12/18/content_17180831.htm

Bogardus, E.S. (1925). Measuring social distance. Journal of Applied Sociology, 9(2), 299-308.

Buys, C.J., \& Bebeau, C.E. (1971). Prejudice social-economic status, and public attitudes toward riots and demonstrations. Psychological Reports, 29(2), 451-458.

Cai, F. (2011). Hukou system reform and unification of ruralurban social welfare. China \& World Economy, 19(3), 33-48.

Chan, K.W. (1994). Cities with invisible walls: Reinterpreting urbanization in post-1949 China. Oxford University Press.

Chan, K.W. (2013, June 13). Urbanization and the Chinese Dream. Retrieved April 29, 2014, from http://english. caixin.com/2013-06-13/100540785.html

Chan, K.W., \& Buckingham, W. (2008). Is China abolishing the hukou system? The China Quarterly, 195(1), 582-605.

Crandall, C.S. (1991). Multiple stigma and AIDS: Illness stigma and attitudes toward homosexuals and IV drug users in AIDS-related stigmatization. Journal of Community \& Applied Social Psychology, 1(2), 165-172.

Crowne, D.P., \& Marlowe, D. (1960). A new scale of social desirability independent of psychopathology. Journal of Consulting Psychology, 24(4), 349.

Dovidio, J.F., Glick, P.E., \& Rudman, L.A. (2005). On the nature of prejudice: Fifty years after Allport. Blackwell Publishing.

Ellemers, N., van Knippenberg, A., Vris, N.D., \& Wilke, H. (1988). Social identification and permeability of group boundaries. European Journal of Social Psychology, 18(6), 497-513.

Ellemers, N., Wilke, H., \& van Knippenberg, A. (1993). Effects of the legitimacy of low group or individual status on individual and collective status-enhancement strategies. Journal of Personality and Social Psychology, 64(5), 766.

Erman, T. (2001). The politics of squatter (gecekondu) studies in Turkey: The changing representations of rural migrants in the academic discourse. Urban Studies, 38(7), 983-1002.

Fishman, R. (2000). The American metropolis at century's end: Past and future influences. Housing policy debate, 11(1), 199213.

Florack, A., Piontkowski, U., Rohmann, A., Balzer, T., \& Perzig, S. (2003). Perceived intergroup threat and attitudes of host community members toward immigrant acculturation. The Journal of Social Psychology, 143(5), 633-648.

Gergen, K.J. (1973). Social psychology as history. Journal of Personality and Social Psychology, 26, 309-320.

Guan, J., \& Liu, L. (2013). Recasting stigma as a dialogical concept: A case study of rural-to-urban migrants in China. Journal of Community \& Applied Social Psychology, 24(2), 75-85.
Henry, P.J., \& Sears, D.O. (2002). The symbolic racism 2000 scale. Political Psychology, 23(2), 253-283.

Hertel, T., \& Zhai, F. (2006). Labor market distortions, ruralurban inequality and the opening of China's economy. Economic Modelling, 23(1), 76-109.

Johnson, D., Terry, D.J., \& Louis, W.R. (2005). Perceptions of the intergroup structure and Anti-Asian prejudice among white Australians. Group Processes \& Intergroup Relations, $8(1), 53-71$.

Kuang, L., \& Liu, L. (2012). Prejudice against rural-to-urban migrants: The role of the hukou system in china. PloS One, 7(11), e46932.

Li, L., Li, S.M., \& Chen, Y. (2010). Better city, better life, but for whom?: The hukou and resident card system and the consequential citizenship stratification in Shanghai. City, Culture and Society, 1(3), 145-154.

Li, X., Zhang, L., Fang, X., Xiong, Q., Chen, X., Lin, D., ... Stanton, B. (2007). Stigmatization experienced by rural-tourban migrant workers in China: Findings from a qualitative study. Journal of World Health and Population, 9(4), 29-43.

Litton, I., \& Potter, J. (1985). Social representations in the ordinary explanation of a 'riot'. European Journal of Social Psychology, 15(4), 371-388.

Mallee, H. (2000). Migration, hukou and resistance in reform China. In E.J. Perry \& M. Selden (Eds.), Chinese society: Change, conflict, and resistance (pp. 83-101). New York: Routledge.

Melander, A., \& Pelikanova, K. (2013). Reform of the hukou system: A litmus test of the new leadership. Retrieved August 16, 2014, from http://ec.europa.eu/economy_finance/ publications/economic_briefs/2013/eb26_en.htm

Miles, R. (1984). The riots of 1958: Notes on the ideological construction of 'race relations' as a political issue in Britain. Immigrants \& Minorities, 3(3), 252-275.

Montgomery, M.R. (2008). The urban transformation of the developing world. Science, 319(5864), 761-764.

Mosse, D., Gupta, S., Mehta, M., Shah, V., Rees, J.F., \& Team, K.P. (2002). Brokered livelihoods: Debt, labour migration and development in tribal western India. Journal of Development Studies, 38(5), 59-88.

Mummendey, A., Klink, A., Mielke, R., Wenzel, M., \& Blanz, M. (1999). Socio-structural characteristics of intergroup relations and identity management strategies: Results from a field study in East Germany. European Journal of Social Psychology, 29(2-3), 259-285.

National Bureau of Statistics of China (2013). The number of rural-to-urban migrants of the fourth quarter report in 2013. Retrieved Feb 16, 2014, from http://data.stats.gov.cn/workspace/index?m=hgjd

Roberts, K. (2001). The determinants of job choice by rural labour migrants in Shanghai. China Economic Review, 12(1), 15-39.

Robinson, J.P., Shaver, P.R., Wrightsman, L.S., \& Andrews, F.M. (1997). Measures of personality and social psychological attitudes (Z.F. Yang, Y.Y. Yang \& Z.X. Zhang, Trans.). Taipei: Yuan Liu Press. 
Schuessler, K., Hittle, D., \& Cardascia, J. (1978). Measuring Responding Desirably with Attitude-Opinion items. Social Psychology, 41(3), 224-235.

Tajfel, H., Billig, M., Bundy, R.P. \& Flament, C. (1971). Social categorization and intergroup behaviour. European Journal of Social Psychology, 1(2), 149-177

Tajfel, H., \& Turner, J.C. (1979). An integrative theory of intergroup conflict. In W.G. Austin \& S. Worchel (Eds.), The social psychology of intergroup relations (pp. 33-47). Monterey, CA: Brooks/Cole.

Tajfel, H., \& Turner, J.C. (1986). The social identity theory of intergroup behavior. In S. Worchel \& W. Austin (Eds.), Psychology of intergroup relation (pp. 7-24). Chicago: Nelson Hall.

Verkuyten, M., \& Reijerse, A. (2008). Intergroup structure and identity management among ethnic minority and majority groups: The interactive effects of perceived stability, legitimacy, and permeability. European Journal of Social Psychology, 38(1), 106-127.

Wang, F.L. (2005). Organizing through division and exclusion: China's hukou system. Stanford University Press.

Wang, M.Y. (2002). Small city, big solution? China's hukou system reform and its potential impacts. disP-The Planning Review, 38(151), 23-29.
Wu, X., \& Treiman, D.J. (2004). The household registration system and social stratification in China: 1955-1996. Demography, 41(2), 363-384.

Xinhua News Agency. (2014, March 17). China's Urbanization Plan 2014-2020. Retrieved May 4, 2014, from http://news.xinhuanet.com/house/wuxi/2014-03-17/ c_119795674.htm

Yang, H., Tian, L., van Oudenhoven, J.P., Hofstra, J., \& Wang, Q. (2010). Urban residents' subtle prejudice towards rural-tourban migrants in China. Journal of Community \& Applied Social Psychology, 20(3), 202-216.

Young, J. (2010). Markets, migrants and institutional change: The dynamics of China's changing Huji system, 19782007 (Doctoral dissertation). Retrived July 20, 2014, from http://researcharchive.vuw.ac.nz/handle/10063/1361

Young, J. (2013). China's hukou system: Markets, migrants and institutional change. Palgrave Macmillan.

Zhao, P., \& Howden-Chapman, P. (2010). Social inequalities in mobility: The impact of the hukou system on migrants' job accessibility and commuting costs in Beijing. International Development Planning Review, 32(3), 363-384.

Zheng, C. (2010, June 8). Chinese farmers accumulate points for hukou. Retrieved from: http://news.xinhuanet.com/ english2010/china/2010-06/08/c_13338908.htm 